\title{
Cooperativismo e sustentabilidade: um estudo sobre a produção cientí- fica na base web of science
}

\author{
Cooperativism and sustainability: a study of the scientific production on web of \\ science base
}

\begin{abstract}
Resumo
Este estudo propõe-se a ampliar o conhecimento do que foi produzido no âmbito científico sobre cooperativismo em sua interface com a temática de sustentabilidade. O trabalho caracteriza-se como exploratório e descritivo, de natureza bibliométrica e utilizou como base de dados os artigos encontrados na Web of Science, no período de 2004 a 2013. Foram analisadas 144 publicações. Pode-se constatar que o maior número de publicações ocorreu nos anos de 2009 e 2011. Os países que mais publicaram na área foram China, Estados Unidos e Espanha, porém os artigos mais citados envolvendo os temas sustentabilidade e cooperativismo, conjuntamente, prozêm dos Estados Unidos, China e Austrália e abordam, respectivamente os assuntos: arranjos institucionais para a redução da pobreza rural e conservação dos recursos; reestruturação de distritos industriais e ampliação de desenvolvimento regional.
\end{abstract}

Palavras-chave: Cooperativismo; Sustentabilidade; Bibliometria.

\begin{abstract}
This study aims to increase knowledge on the scientific production related to cooperatives linked to sustainability on Web of Science database, in period of 2004 to 2013. The job is characterized as exploratory and descriptive, because is a bibliometric study of nature. As a result of the 144 publications analyzed it was found that the highest number of publications occurred in the years of 2009 and 2010. The Countries that have higher number of publications in the area were China, United States and Spain, but the most cited articles covering topics sustainability and cooperative jointly come from the United States, China and Australia respectively and relate to the following matters: institutional arrangements for rural poverty reduction and resource conservation; restructuring of industrial districts, regional development and expansion about a sustainable tourism industry.
\end{abstract}

Keywords: Cooperatives, Sustainability, Bibliometic study.

\footnotetext{
Luciano Pastório da Fonseca ${ }^{1}$, Lúcia Rejane da Rosa Gama Madruga, Vera Maria de Souza Mazza, Maisa Gomide Teixeira e Letiane Streck

${ }^{1}$ Universidade Federal de Santa Maria; Rua Silva Jardim, 1994, ap. 602; Santa Maria, Brasil - lucianopastorio@gmail.com
} 


\section{Introdução}

$\mathrm{A}$ s organizações estão, cada vez mais, buscando alternativas para manterem-se competitivas e capazes de enfrentarem os desafios impostos pelos cenários aos quais estão expostas. Para aumentar suas chances de sobrevivência, em sociedade, o homem sempre se valeu de cooperação, desde o início da civilização. Com as transformações sociais e no modo de produção, ao longo dos anos, dois temas possuem destaque e são objetos deste estudo: O Cooperativismo e a Sustentabilidade.

As cooperativas foram, desde o seu início, uma expressão de natureza empresarial do movimento operário. Sendo assim, a vivência das regras de mercado são traços de sua identidade, porém o siginificado das atividades neste tipo de organização são presumivelmente mais amplas (NAMORADO, 1993). Com o capitalismo moderno, conforme Namorado (1993), as cooperativas surgiram como organizações integradas, associativas, um conjunto de organizações que representaram, no século XIX, o início da estruturação do movimento operário. Emergiram em consonância com os sindicatos e com os partidos políticos operários, como uma intervenção traduzida em atividade empresarial.

Foi no período de vivência do Capitalismo Tradicional, período em que os recursos naturais eram abundantes e a mão-de-obra escassa, que imperou o pensamento de que se deveria explorar o máximo possível estes recursos para a obtenção de lucros abundantes. Esta concepção da produção em organizações, trouxe uma amplitude de benefícios à sociedade, mas à custa de um preço bastante alto: a liquidação dos recursos naturais, fundamentais para a existência humana (HAWKEN et al., 2000).

O Cooperativismo é um movimento, uma filosofia de vida e um modelo socioeconômico capaz de unir desenvolvimento econômico e bem-estar social. Seus fundamentos são: participação democrática, solidariedade, independência e autonomia (OCB Sescoop, 2014). Esse conceito possui convergência com o conceito de sustentabilidade no qual o desenvolvimento econômico e o bem-estar social aliam-se à preservação dos recursos ambientais e assim propiciam um "desenvolvimento que satisfaz as necessidades do presente sem comprometer a capacidade das gerações futuras para satisfazer suas próprias necessidades" (WCED, 1987, p. 42).

Portanto, percebe-se imbricamento entre sustentabilidade e cooperativismo, porém, pouco se sabe a respeito dos estudos que têm retratado em conjunto estes temas. Ressalta-se assim a contribuição deste estudo que objetiva analisar o conhecimento produzido no âmbito científico do cooperativismo em sua interface com o tema de sustentabilidade. O estudo interessa não só às organizações cooperativas tendo em vista que As iniciativas organizacionais, cada vez mais, estão buscando o exercício de um desenvolvimento vinculado à resolução de alguns conflitos latentes na sociedade. Desta forma, pretendem compatibilizar o crescimento a um padrão que se mostre sustentável procurando respeitar os limites naturais e as liberdades substantivas dos indivíduos (SEN, 2000).

\section{Referencial teórico}

Este segmento tem como objetivo apresentar o referencial teórico que serviu de suporte para o presente trabalho, ou seja: conceitos de cooperativismo e sustentabilidade.

\subsection{Cooperativas e cooperativismo}

Etimologicamente o termo cooperação origina-se do verbo latino cooperari, de cum e operari = operar juntamente com alguém. Significa a prestação de auxílio para um fim comum. Cooperação, do ponto de vista sociológico, é uma forma de integração social e pode ser entendida como ação conjugada, na qual as pessoas se unem de modo formal ou informal, para alcançar o mesmo objetivo. Por sua vez, o cooperativismo corresponde à doutrina, ou seja, à base das realizações cooperativas visando à renovação social através da cooperação (PINHO, 1966).

Conforme a Organização das Cooperativas Brasileiras OCB (2014), cooperativa é uma associação autônoma de pessoas que se unem voluntariamente, para satisfazer aspirações e necessidades econômicas, sociais e culturais comuns, por meio de uma empresa de propriedade coletiva e democraticamente gerida. Essas pessoas baseiam-se em valores de ajuda mútua e responsabilidade, democracia, igualdade, equidade e solidariedade. $\mathrm{Na}$ tradição dos seus fundadores, os membros das cooperativas acreditam nos valores éticos da honestidade, transparência, responsabilidade social e preocupação pelo seu semelhante.

As cooperativas são, portanto, consideradas entidades singulares e podem ser vistas como uma sociedade de pessoas cujo objetivo é a prestação de serviços e não o lucro. Neste tipo de organização o cooperado é visto como dono e usuário e o retorno dos resultados é proporcional ao valor das operações com a cooperativa (YOUNG, 2008).

Para Bialoskorski (1998), as cooperativas podem ser analisadas como organizações contratuais e argumenta que estas apresentam uma governança de híbrida a hierárquica em função das relações de contratos entre os produtores associados e a cooperativa. Um sistema desse tipo oferece condições de governança de híbrida até hierárquica que, na dependência de níveis elevados de especificidades de ativos, possibilitam menores custos de transação.

O movimento cooperativista teve início na Inglaterra e França como oposição operária às consequências do liberalismo econômico praticado no fim do século XVIII e início do século XIX. Com a Revolução Industrial na 
Inglaterra, a mão-de-obra perdeu grande poder de troca, a longa jornada de trabalho e os baixos salários trouxeram muitas dificuldades socioeconômicas para a população. Diante desta crise surgiram, lideranças, em meio à classe operária que criaram associações de caráter assistencial. Esta experiência não teve resultado positivo e, baseados nesses fracassos foram procuradas novas formas de organização e, concluíram que, com a organização formal, a qual denominaram cooperativa, era possível superar as dificuldades, desde que fossem considerados valores humanistas e praticadas regras, normas e princípios próprios (PINHO, 1966).

Desta forma um grupo de operários, em sua maioria tecelões, se reuniu para avaliar suas ideias, respeitando seus costumes, tradições e estabeleceram normas e metas para a organização de uma cooperativa. Após um ano de trabalho conseguiram abrir um pequeno armazém cooperativo, no bairro de Rochdale-Manchester (Inglaterra). Com isso, nascia a primeira cooperativa moderna do mundo: A Sociedade dos Probos de Rochdale. (PINHO, 1966).

No Brasil, de acordo com Singer (2002), o cooperativismo foi trazido pelos europeus e difundido através de cooperativas de consumo e cooperativas agrícolas nas cidades e no campo, respectivamente. Conforme a OCB (2014), o Movimento Cooperativista Brasileiro surgido no final do século XIX, foi estimulado por funcionários públicos, militares, profissionais liberais e operários, para atender às suas necessidades. A primeira cooperativa de consumo criada em área urbana iniciou suas atividades em 1889 e era denominada Sociedade Cooperativa Econômica dos Funcionários Públicos de Ouro Preto-MG. Posteriormente, se expandiu para Pernambuco, Rio de Janeiro e outros estados.

Em 1902, surgiram as cooperativas de crédito no Rio Grande do Sul e, a partir de 1906, nasceram e se desenvolveram as cooperativas no meio rural, idealizadas por produtores agropecuários; muitos deles de origem alemã e italiana. Os imigrantes trouxeram de seus países de origem a bagagem cultural, o trabalho associativo e a experiência de atividades familiares comunitárias que os motivaram a organizar-se em cooperativas.

No Brasil, o cooperativismo é legalmente representado pela Organização das Cooperativas Brasileiras - OCB. A Lei que rege o cooperativismo no Brasil é a de no 5.764 , de 16 de dezembro de 1971, que define no artigo $3^{\circ}$ a cooperativa como uma "sociedade de pessoas com formas e natureza jurídica própria, não sujeitas à falência, organizadas para prestar serviços aos associados, e sem finalidade lucrativa própria".

No ano de 2011 estavam registradas no Brasil, 1.523 cooperativas do ramo agropecuário, dado que representa uma queda de $2 \%$ na comparação com o ano anterior. Apesar disso, o número de pessoas cooperadas no setor agropecuário cresceu 3\%, chegando a 969.541 mil - só menor do que os envolvidos nos setores de crédito e consumo (SESCOOP, 2011). Além disso, o setor foi responsável pela geração de 155.896 empregos diretos.

Tamanha representatividade pode ser medida nos principais índices econômicos do país. Em 2009 o setor foi responsável por 37,2\% do Produto Interno Bruto (PIB) Agrícola do país, e suas exportações renderam US \$ 3,6 bilhões. Apesar dos números, o Ministério da Agricultura, Pecuária e Abastecimento (MAPA ainda aponta que a população brasileira apresenta um índice baixo de participação em entidades associativas, cuja média mundial é de aproximadamente $40 \%$ da população.

\subsection{Sustentabilidade}

A maior conscientização de que os recursos naturais são finitos emerge nas décadas de 60 e 70, a chamada era nuclear, através de movimentos ambientalistas e comunidade em geral, diante das devastações florestais e ambientais surgindo grandes pressões de ambientalistas, comunidades e organizações internacionais com o objetivo de minimizar tais impactos (MARTINS et al.,2012).

Partindo deste cenário, surge o conceito de sustentabilidade em 1987, com a publicação de Nosso Futuro Comum, o relatório da Comissão Mundial sobre Meio Ambiente e Desenvolvimento (CMMAD). Desenvolvido por uma comissão de especialistas e instituída pela Organização das Nações Unidas, no qual a sustentabilidade global foi definida como a habilidade para o "desenvolvimento que satisfaz as necessidades do presente sem comprometer a capacidade das gerações futuras para satisfazer suas próprias necessidades" (WCED, 1987, p. 42).

Em 1997, Elkington, em seu livro "Cannibals with forks: the triple bottom line of 21st century business", cunhou um conceito de sustentabilidade no qual apresenta uma expansão do modelo tradicional de negócios - o chamado Triple Bottom Line (TBL). O modelo de Elkington difere do modelo tradicional de negócio - que só considerava fatores econômicos na avaliação de uma empresa - para um novo modelo, que passa a considerar a performance ambiental e social da organização além da financeira (ELKINGTON, 1997).

Para Elkington (1997), a operacionalização do conceito de sustentabilidade é representada na forma de três pilares: econômico, social e ambiental, como apresenta a Figura 01.

Para Elkington (1997) o tripé da sustentabilidade, ou seja, as três dimensões (social, econômica e ambiental) estão intrínsecas no conceito de empresa sustentável, ou seja, devem estar integradas, de modo que na esfera ambiental, os recursos sejam aproveitados de maneira eficaz. Apresenta-se, com base em Elkington (1997), o que cada dimensão representa:

Social - Trata-se do capital humano de um empreendimento, comunidade, sociedade como um todo. Refere-se também a salários justos e estar condizente com a legislação trabalhista. Essa dimensão enfatiza que é preciso pensar em outros aspectos nas organizações 


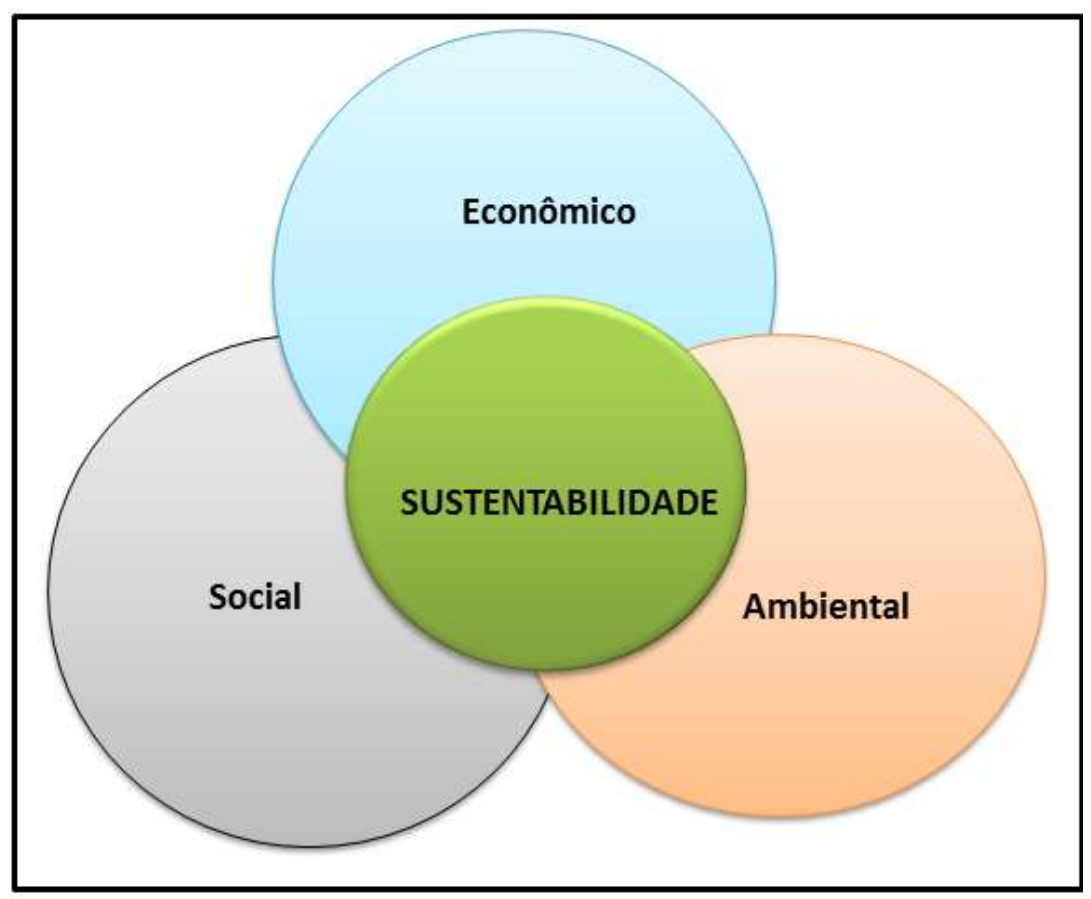

Figura 01 - Modelo Triple Bottom Line - TBL

Fonte: Elaborado com base em Elkington (1997)

além do bem estar dos funcionários. Segundo Donaire (2011), as organizações devem reconhecer sua responsabilidade para com a sociedade em geral, implicando em compromissos que incluem filantropia, equidade de oportunidades, serviços e benefícios sociais que contemplem o interesse público da coletividade.

A dimensão Ambiental, segundo Elkington (1997) - Refere-se ao capital natural de um empreendimento ou sociedade. É a perna ambiental do tripé. Aqui assim como nos outros itens, é importante pensar no pequeno, médio e longo prazo. A princípio, praticamente toda atividade econômica tem impacto ambiental negativo. Nesse aspecto, a empresa ou a sociedade deve pensar nas formas de amenizar esses impactos e compensar o que não é possível. Uma empresa que utiliza determinada matéria-prima deve planejar formas de repor os recursos ou, se não é possível, diminuir o máximo possível o uso desse material, assim como saber medir a pegada de carbono. Entende-se "pegada de carbono" (carbon footprint), como a medida do impacto das atividades humanas sobre as emissões de gases do efeito estufa, ou seja, condiz com a quantidade de dióxido de carbono equivalente liberada na realização de cada atividade.

No que se refere à dimensão Econômica Elkington (1997) caracteriza como a que envolve temas ligados à produção, distribuição e consumo de bens e serviços e deve-se levar em conta os outros aspectos que envolvem o setor em que a empresa atua. Enfatiza-se a viabilidade financeira, isto é, a necessidade das organizações de prosperarem economicamente como empresa.
O modelo da TBL é utilizado para orientar as organizações no direcionamento de ações e estratégias para a sustentabilidade. É necessário que as empresas repensem seus modelos produtivos para atingirem a sustentabilidade de forma a não causarem impactos negativos, que estejam contribuindo para a recuperação de áreas degradadas ou oferecendo produtos e serviços que contribuam para a melhoria da performance ambiental dos consumidores.

Segundo Barbieri et al., (2010), em princípio, as organizações passaram a inserir o desenvolvimento sustentável em suas estratégias em razão das pressões externas e como respostas às cobranças de grupos ambientalistas, entidades governamentais e da sociedade civil como um todo. No entanto, nas últimas décadas as empresas passaram a adotar o desenvolvimento sustentável como fator que pode agregar valor à organização, torná-la mais competitiva, diferenciando-a das demais e, até como um fator importante para garantir a sobrevivência do negócio.

Para Sachs (1990), a sustentabilidade constitui-se num conceito dinâmico que leva em conta as necessidades crescentes das populações num contexto internacional em constante expansão. A sustentabilidade, para este mesmo autor, tem como base cinco dimensões principais, que são: a sustentabilidade social, a econômica, a ecológica, a geográfica e a cultural.

A sustentabilidade social refere-se a uma melhor distribuição de renda e à redução das diferenças sociais. A sustentabilidade econômica está vinculada ao fluxo constante de inversões públicas e privadas, 
além da correta administração dos recursos naturais. A sustentabilidade ecológica refere-se ao uso efetivo dos recursos existentes nos diversos ecossistemas e, como um dos resultados, a mínima deterioração ambiental. A sustentabilidade geográfica está ligada a uma espacialização rural-urbana mais equilibrada e a.Sustentabilidade cultural procura a realização de mudanças em harmonia com a continuidade cultural vigente.

Em 2002, Sachs acrescentou mais quatro dimensões de sustentabilidade: ambiental, territorial (em lugar de geográfica), política nacional e política internacional. A sustentabilidade ambiental permitiria que ecossistemas naturais realizassem autodepuração. A territorial visa à eliminação de disparidades inter-regionais, a destinação igualitária de investimentos públicos e a conservação da biodiversidade pelo eco-desenvolvimento.

A sustentabilidade no que refere-se às políticas nacionais passaria por um nível razoável de coesão social, democracia e capacidade institucional do Estado em implantar um projeto nacional. No que refere-se às políticas internacionais, a sustentabilidade passaria pela garantia de paz assegurada pelo fortalecimento da ONU, controle do sistema financeiro internacional, cooperação científica e diminuição das disparidades sociais entre os hemisférios norte-sul (SACHS, 2002).

Tendo por base o conceito de sustentabilidade, a organização sustentável possui o desafio de unir o bem-estar econômico, a equidade social e a proteção ao meio ambiente a partir de ações de longo prazo, assim fazendo as organizações desenvolverem modelos de negócios mais comprometidos com a sustentabilidade.

Desta forma, as organizações passam a desenvolver modelos de negócios mais comprometidos com o futuro e com a sustentabilidade passando a avaliar as consequências e impactos de suas ações no ambiente organizacional sob o viés social, ambiental e do lucro financeiro (ALIGLERI; ALIGLERI; KRUGLIANSKAS, 2009).

\section{Metodologia}

Este estudo foi desenvolvido a partir de uma pesquisa bibliométrica, objetivando ampliar o conhecimento referente à Cooperativismo e Sustentabilidade, para tal, foram usadas as palavras cooperatives and sustai$\mathrm{nab}^{*}$ na base de dados Web of Science no período de 2004 a 2013, foram selecionados as seguintes áreas de interesse: Economia (economics), Negócios (business), Administração Pública (public administration), Gestão (management), Negócios Financeiros (business finance).

Segundo Silva (2004), a bibliometria possui como objetivo analisar a atividade científica ou técnica através do estudo quantitativo das publicações. Complementando esta ideia, Rostaing (1997) afirma que o estudo bibliométrico consiste na aplicação dos métodos estatísticos ou matemáticos sobre o conjunto de referências bibliográficas. Para Macedo, Casa Nova e Almeida (2007), a bibliometria ajuda a conhecer o estágio em que uma pesquisa, em determinada área, encontra-se. O estudo possui abordagem quantitativa, tendo em vista que procurou quantificar algumas variáveis referentes à produção científica sobre Cooperatives and Sustainab* (Cooperativismo e Sustentabilidade).

A seguir, a figura 2 colabora com a explicação das etapas da pesquisa na plataforma Web of Science e apresenta os resultados encontrados.

A pesquisa na plataforma Web of Science foi realizada em 03 etapas. A primeira etapa caracteriza-se pela pesquisa do tópico Cooperatives and Sustainab*, filtro que localizou um total de 789 artigos relacionados a esta temática. Na etapa posterior, foram considerados filtros nas áreas temáticas de economia, negócios, administração pública, gestão e finanças, reduzindo para 144 o número de artigos encontrados. Por fim, o objetivo da etapa 03 consistiu em caracterizar e classificar as publicações encontradas por ano de publicação, autores, instituições vinculadas, países de origem e análise das publicações

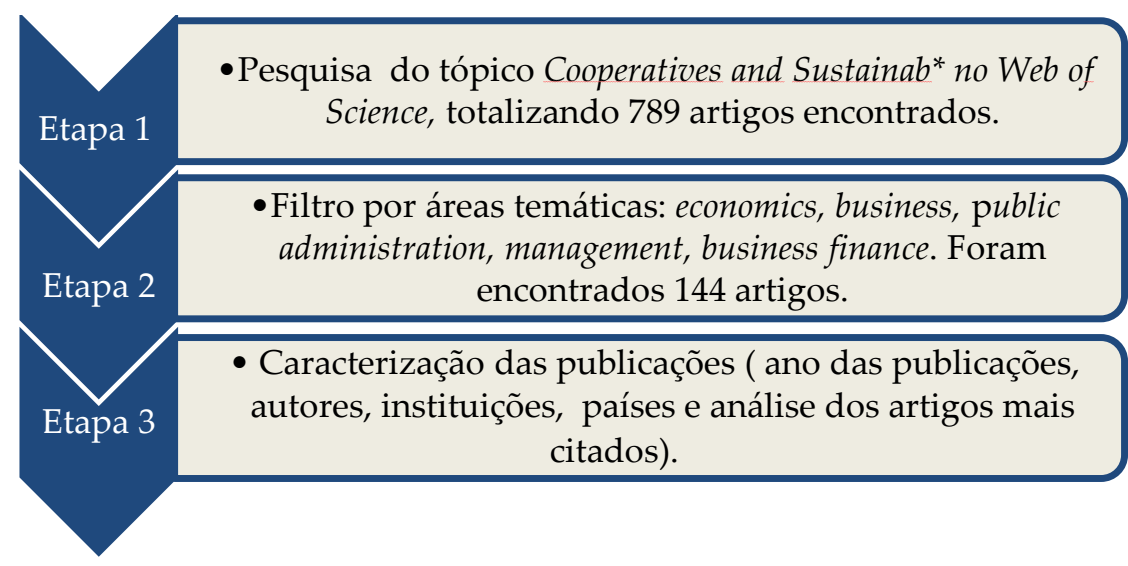

Figura 2: Etapas da Pesquisa

Fonte: Elaborada pelos Autores 
mais citadas.

De acordo com a sequência das etapas citadas foi possível encontrar 144 artigos coerentes aos objetivos propostos no estudo e a partir deles, tornou-se possível avaliar os resultados encontrados.

\section{Análise dos resultados}

A descrição e a análise dos resultados encontrados a partir do processamento das informações extraídas dos 144 artigos selecionados estão apresentadas a seguir, tomando como ponto de partida a evolução quantitativa da produção científica sobre cooperativismo em sua interface com a temática da sustentabilidade no período de 2004 a 2013. Posteriormente serão analisadas as publicações por instituição de ensino, por países, autores e os artigos mais citados.

\subsection{Análise de publicações por ano de publica- ção}

A Figura 3 apresenta as publicações sobre a cooperativas e sustentabilidade, no período de 2004 a 2013, usando-se o descritor cooperatives and sustainab*.

A Figura 3 permite visualizar que entre os anos de 2004 e 2006 ocorre um aumento no número de publicações, já a partir de 2007 há uma oscilação no número de publicações até o ano de 2013 e, se for considerado o número de publicações de 2004, comparativamente ao ano de 2011, ano com maiores publicações, verifica-se um aumento superior a nove vezes. O ano de 2011 é o ano de maior número de publicações, o que se pode justificar devido ao fato de que no ano de 2012 ocorreu o Evento Mundial de Desenvolvimento Sustentável, Rio+20.

\subsection{Análise de publicações por instituição}

Na Figura 4 pode-se perceber que as principais instituições que publicam sobre cooperatives and sustainab* são Chinesas, verifica-se, porém, que não há uma grande disparidade no número de publicações, visto que a instituição que mais publicou no período de 2004 a 2013 publicou quatro trabalhos, a segunda instituição com o maior número de publicações aparece com três trabalhos, as demais aparecem com duas publicações cada.

\subsection{Análise de publicações por país}

A Figura 5 representa as publicações de acordo com os países que mais publicam, onde percebe-se que a China aparece como o país que mais publicou sobre o assunto, tendo quarenta publicações, o que pode ser justificado pelo país possuir as instituições que mais publicam sobre o assunto. O segundo país que mais publicou sobre o assunto é os Estados Unidos, com vinte e duas publicações.

\subsection{Análise das publicações por autores}

A partir da Figura 6, pode-se perceber que não há

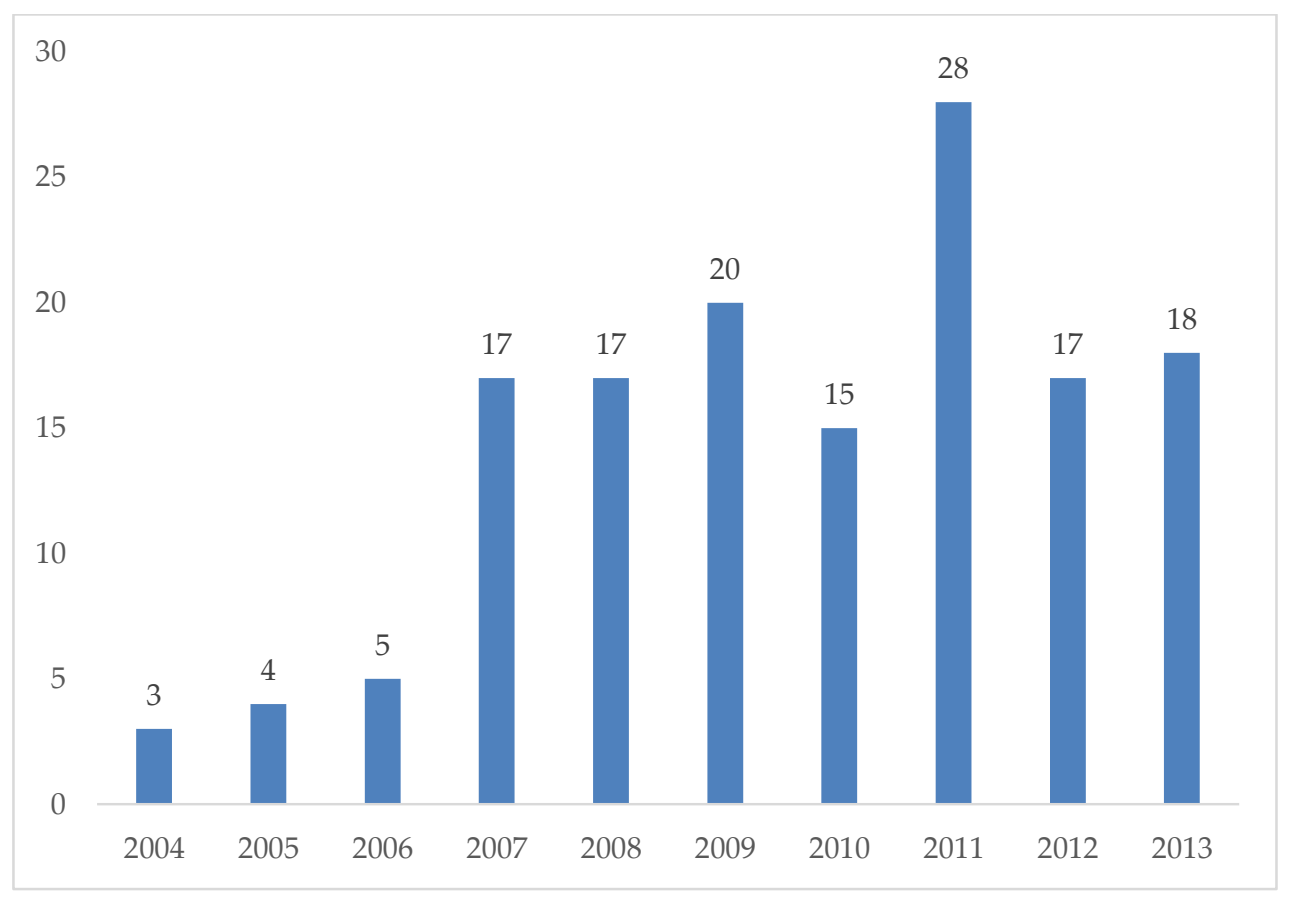

Figura 3 : Ano das publicações

Fonte: Elaborada pelos autores 


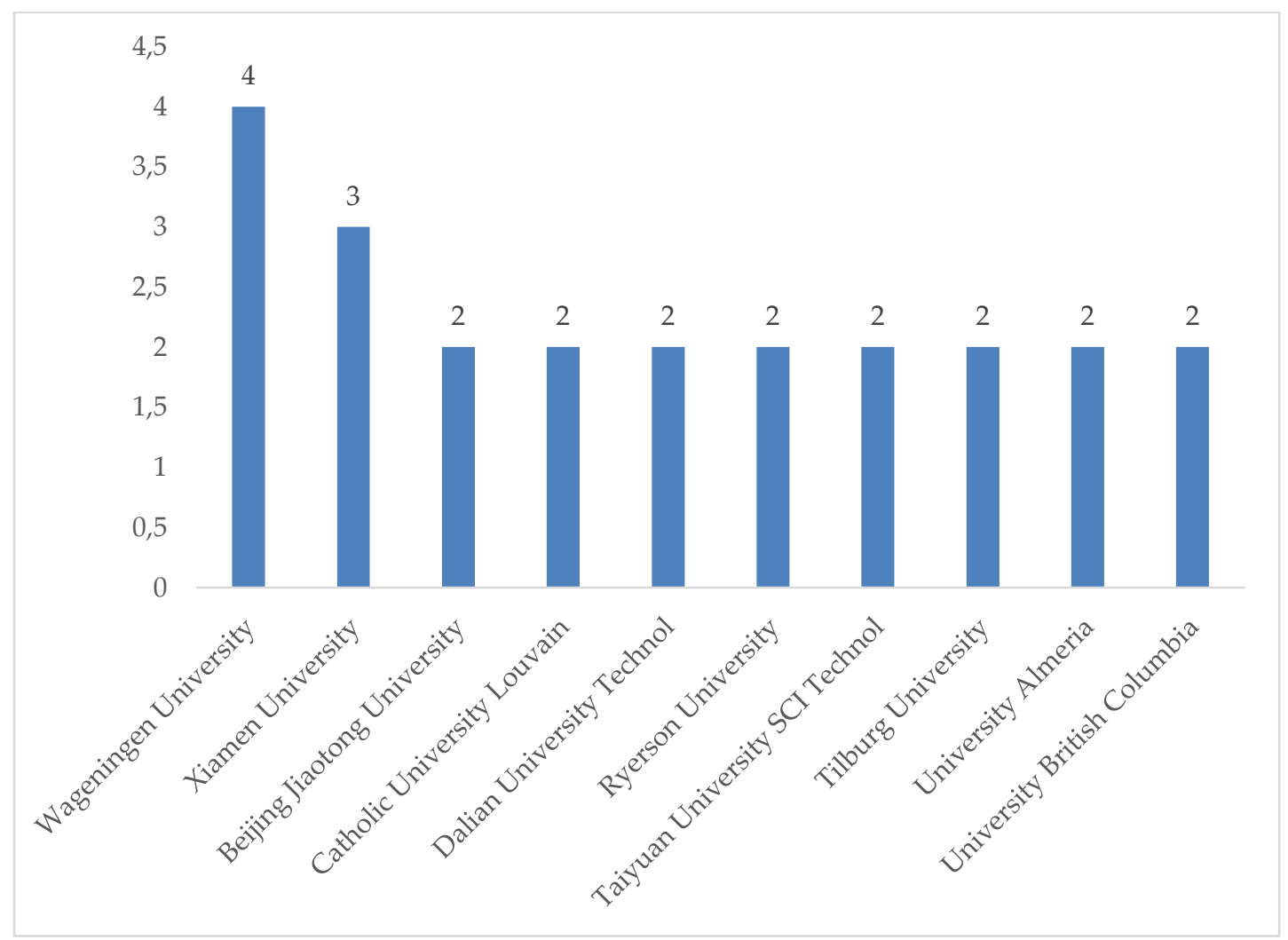

Figura 4: Publicações por instituição

Fonte: Elaborada pelos autores

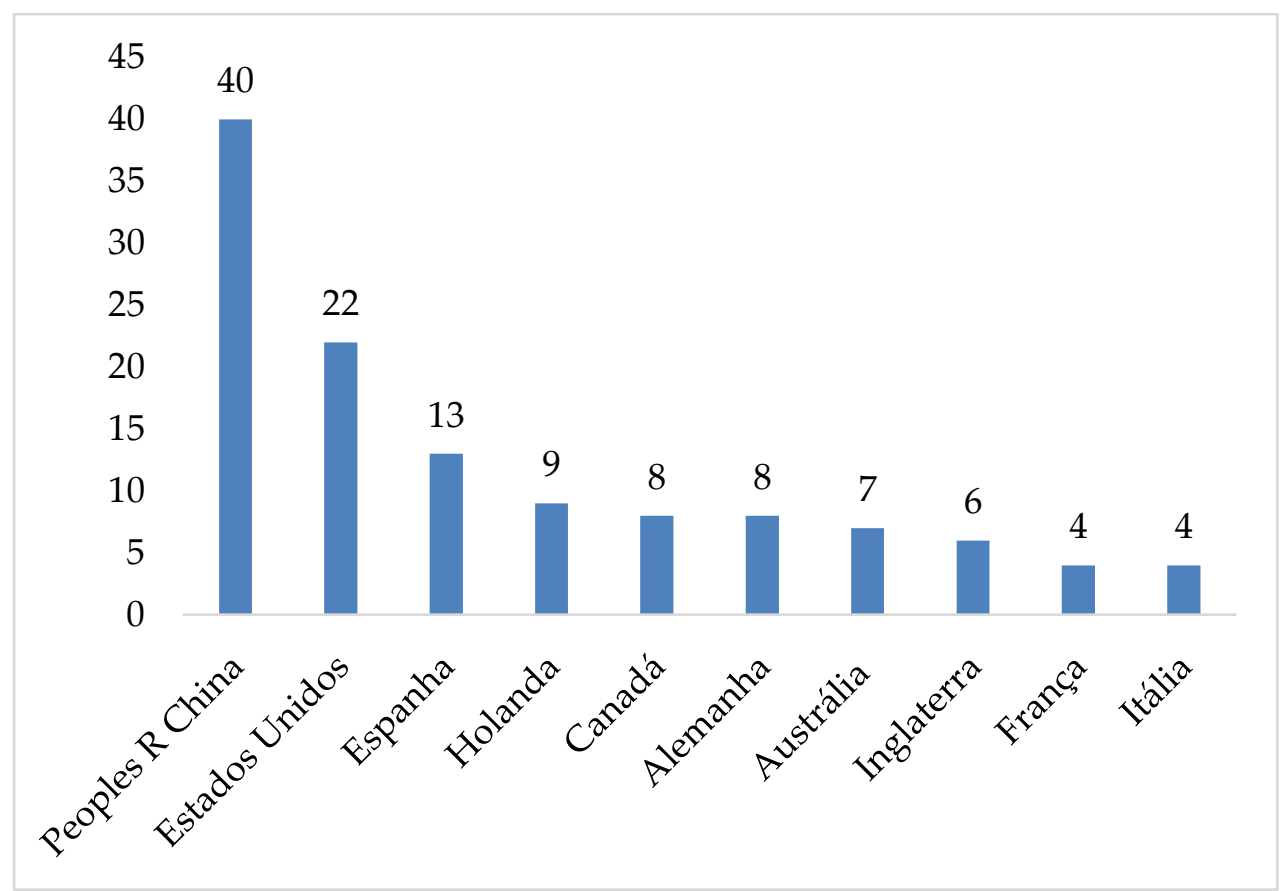

Figura 5: Publicações por país

Fonte: Elaborado pelos autores 
uma grande diferença entre o número de publicações dos dez principais autores, visto que os autores que mais publicaram são Camison C. e Galdeano-Gomez E. ambos com duas publicações cada, os demais autores aparecem com uma publicação cada. suprimentos, etanol e biodiesel, ilustraram os desafios das políticas recentes do governo e as tentativas da indústria para melhorar a sustentabilidade na cadeia de abastecimento.

Como principais conclusões o artigo apresenta que,

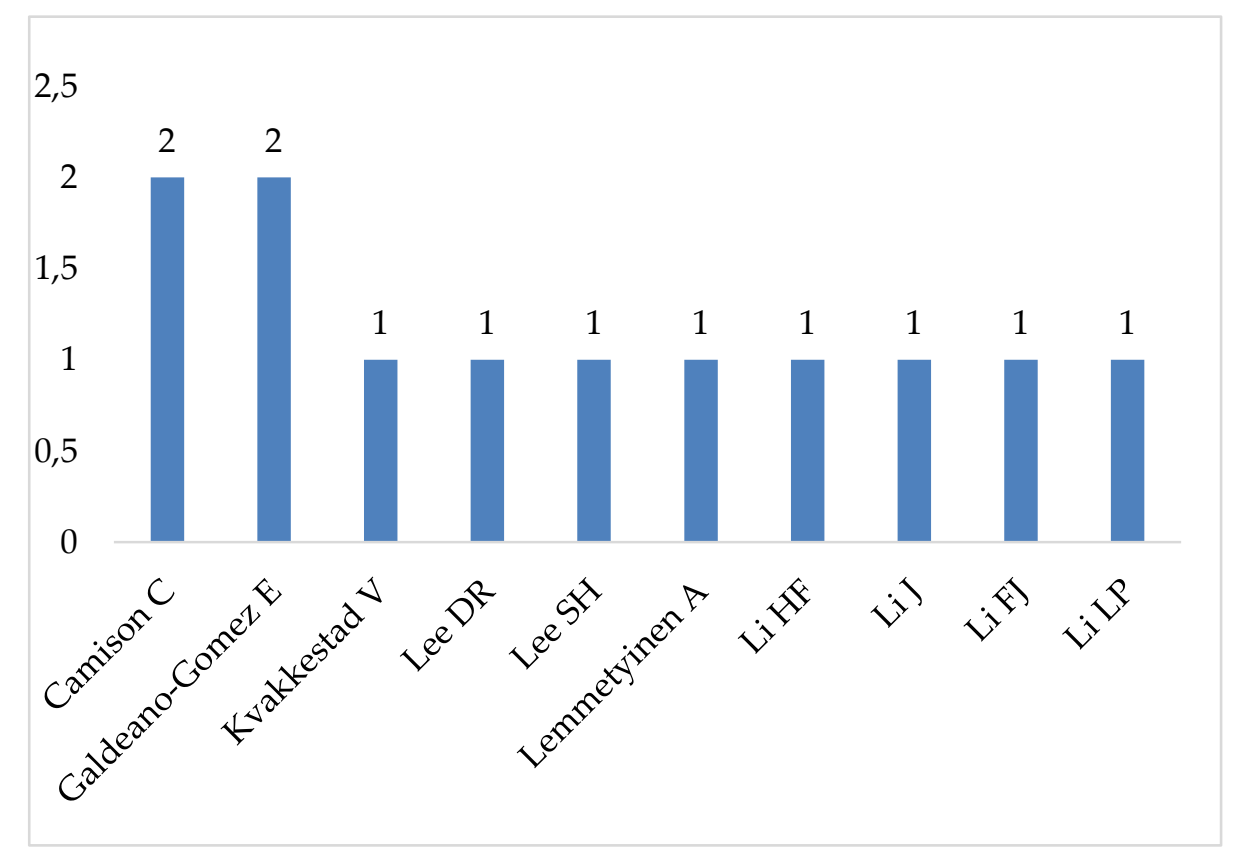

Figura 6: Publicações por autores

Fonte: Elaborada pelos autores

\subsection{Análise dos artigos mais citados}

Como indicado no Quadro 1, entre os dez artigos mais citados apenas um é de autoria de um dos autores com maior número de publicações. Pode-se perceber, também, que dentre eles há um artigo de uma pesquisadora brasileira em parceria com pesquisador canadense. Este resultado pode indicar a importância do trabalho de associação entre pesquisadores internacionais e sugerir que o Brasil é um país bastante representativo em termos de cooperativismo e sustentabilidade

$\mathrm{O}$ referido artigo: Incorporating impoverished communities in sustainable supply chains, foi publicado no ano de 2010 e possui 20 citações. A publicação versa sobre as chamadas recentes no Brasil para incluir considerações sociais e ambientais nas cadeias de suprimentos, analisando o abastecimento de matérias-primas provenientes de comunidades carentes para reduzir os impactos ambientais e exclusão social na produção de biocombustíveis.

O estudo foi realizado no Brasil por este ser grande produtor e consumidor de biocombustível. A metodologia utilizada foi o estudo de caso com base em entrevistas e grupos focais com membros da cadeia de suprimentos e outras partes interessadas. Dois casos de cadeia de embora o governo e a indústria reconheçam a importância de oferecer oportunidades para as comunidades pobres nas cadeias de fornecimento de biocombustíveis, continuam a existir pressões consideráveis para economizar às custas das políticas da cadeia de suprimento sustentável. O abastecimento por agricultores pobres que não têm conhecimento básico de negócios, a desconfiança da indústria e políticas de governo, compõe desafios para a sustentabilidade nesta cadeia de suprimentos. Nesta dinâmica o cooperativismo é citado.

Conforme apresentado no Quadro 1, o artigo com maior número de citações englobando os temas cooperativismo e sustentabilidade de forma conjunta foi: Institutional arrangements for rural poverty reduction and resource conservation. O referido artigo foi publicado no ano de 2005 e foi citado 37 vezes. A publicação refere-se à arranjos institucionais para a redução da pobreza rural e a conservação dos recursos. Neste artigo as palavras cooperativa, cooperação e sustentabilidade referem-se mais ao trabalhar conjuntamente e não diretamente ao conceito apresentado no referencial teórico.

\section{Conclusão}


Quadro 1: Artigos mais citados

\begin{tabular}{|c|c|}
\hline Artigos Mais Citados & $\begin{array}{l}\text { Número } \\
\text { de } \\
\text { Citações }\end{array}$ \\
\hline $\begin{array}{l}\text { How leaders influence organizational effectiveness } \\
\text { Por: Yukl, Gary } \\
\text { LEADERSHIP QUARTERLY. Volume: 19, Edição: 6, Páginas: 708-72. Publicado: DEC } 2008\end{array}$ & 43 \\
\hline $\begin{array}{l}\text { Institutional arrangements for rural poverty reduction and resource conservation* } \\
\text { Por: Barrett, CB; Lee, DR; McPeak, JG } \\
\text { WORLD DEVELOPMENT. Volume: 33, Edição: } 2 \text { Páginas: 193-197 Publicado: FEB } 2005\end{array}$ & 37 \\
\hline $\begin{array}{l}\text { Restructuring industrial districts, scaling up regional development: A study of the Wenzhou } \\
\text { model, China* } \\
\text { Por: Wei, Yehua Dennis; Li, Wangming; Wang, Chunbin } \\
\text { ECONOMIC GEOGRAPHY Volume: } 83 \text { Edição: } 4 \text { Páginas: 421-444 Publicado: OCT } 2007\end{array}$ & 31 \\
\hline $\begin{array}{l}\text { Getting closer to whales - passenger expectations and experiences, and the management of } \\
\text { swim with dwarf minke whale interactions in the Great Barrier Reef* } \\
\text { Por: Valentine, PS; Birtles, A; Curnock, M; et al. } \\
\text { TOURISM MANAGEMENT Volume: } 25 \text { Edição: } 6 \text { Páginas: } 647-655 \text { Publicado: DEC } 2004\end{array}$ & 31 \\
\hline $\begin{array}{l}\text { Fair Trade organic coffee production in Nicaragua - Sustainable development or a poverty } \\
\text { trap?* } \\
\text { Por: Valkila, Joni } \\
\text { ECOLOGICAL ECONOMICS Volume: } 68 \text { Edição: } 12 \text { Páginas: } 3018-3025 \text { Publicado: OCT } 15 \\
2009\end{array}$ & 30 \\
\hline $\begin{array}{l}\text { Sustainable homeservices? Toward household services that enhance ecological, social and } \\
\text { economic sustainability?* } \\
\text { Por: Halme, M; Jasch, C; Scharp, M } \\
\text { ECOLOGICAL ECONOMICSVolume: } 51 \text { Edição: 1-2 Páginas: 125-138 Publicado: NOV } 12004\end{array}$ & 21 \\
\hline $\begin{array}{l}\text { Incorporating impoverished communities in sustainable supply chains* } \\
\text { Por: Hall, Jeremy; Matos, Stelvia } \\
\text { INTERNATIONAL JOURNAL OF PHYSICAL DISTRIBUTION \& LOGISTICS MANAGEMENT } \\
\text { Volume: } 40 \text { Edição: } 1-2 \text { Páginas: } 124-147 \text { Publicado: } 2010\end{array}$ & 20 \\
\hline $\begin{array}{l}\text { On the sustainability of common property resources* } \\
\text { Por: Oses-Eraso, Nuria; Viladrich-Grau, Montserrat } \\
\text { JOURNAL OF ENVIRONMENTAL ECONOMICS AND MANAGEMENT Volume: } 53 \text { Edição: } 3 \\
\text { Páginas: } 393-410 \text { Publicado: MAY } 2007\end{array}$ & 20 \\
\hline $\begin{array}{l}\text { Sustainable development in small island developing states: Agricultural intensification, } \\
\text { economic development, and freshwater resources management on the coral atoll of Tongatapu* } \\
\text { Por: van der Velde, M.; Green, S. R.; Vanclooster, M.; et al. } \\
\begin{array}{lll}\text { ECOLOGICAL ECONOMICSVolume: } 61 & \text { Edição: 2-3 Páginas: 456-468 Publicado: MAR } 12007\end{array}\end{array}$ & 16 \\
\hline $\begin{array}{l}\text { Ecological and economic sustainability in fishery management: A multiagent model for } \\
\text { understanding ocmpetition and cooperation* } \\
\text { Por: BenDor, T; Scheffran, J; Hannon, B. } \\
\text { JOURNAL ECOLOGICAL ECONOMICS Volume: } 68 \text { Edição: } 4 \text { Páginas: 1061-1073 Publicado: } \\
\text { APR } 2010\end{array}$ & 15 \\
\hline
\end{tabular}


Esse estudo revelou o caráter convergente da sustentabilidade com o cooperativismo nos artigos analisados, retratando a busca pelo desenvolvimento sustentável. Além disso, demonstrou que nos últimos anos a comunhão destes temas apresentou-se de forma crescente nas publicações.

Ao relacionarmos os termos cooperatives and sustainab* na base de dados Web of Science percebe-se que os artigos encontrados referem-se, em sua maioria, ao conceito de sustentabilidade e se relacionam à cooperação, mas não diretamente ao conceito de cooperativas como entidades, sociedade de pessoas cujo objetivo é a prestação se serviços e não o lucro mas que possui princípios claros.Analisando-se os artigos mais citados percebe-se que, talvez haja o surgimento de cooperativas "formais", ou seja, que correspondam ao conceito exposto neste referencial teórico, porém estas ainda estão em fase de organização. Uma das sugestões para estudos futuros é o estudo das cooperativas como arranjo institucional mais eficiente para atingir a sustentabilidade.

Quanto aos países que mais publicaram, os dados revelaram que a China apresentou o maior número de estudos, sendo que, entre as principais instituições, destaca-se a Wageningen University. Um dos fatores que se poderia inferir para esta constatação é a preocupação da China com o meio ambiente e sua densidade populacional.

Este trabalho não deve ser considerado conclusivo, pois, uma investigação com mais propriedade do conhecimento produzido sobre os temas, requer maior profundidade de análise. Sugere-se novos estudos que possam continuar a pesquisa ampliando o seu escopo com a mesma base de dados. Ainda, é possível aprofundar este estudo, partindo dos tópicos quentes e focalizando as principais temáticas em cada um deles, permitindo a identificação de suas principais implicações. Outra forma de continuidade pode-se dar pela utilização de outra base de dados a fim de complementar, comparar, confirmar ou substituir os resultados obtidos neste trabalho.

\section{Referências}

ALIGLERI, L.; ALIGLERI, L. A.; KRUGLIANSKAS,

I. Gestão socioambiental: responsabilidade e sustentabilidade do negócio. São Paulo: Atlas 2009. p. 245.

BARBIERI, J. C.; VASCONCELOS, I. F. G. de; ANDREASSI, T.; VASCONCELOS, F. C. de. Inovação e sustentabilidade: novos modelos e proposições. Revista de Administração de Empresas, São Paulo, v. 50, n. 2, p. 146-154, jun. 2010.

BIALOSKORSKI, S. Cooperativas: economia, crescimento e estrutura de capital. Piracicaba, 1998. 257p. Tese de Doutorado. ESALQ/USP.

DONAIRE, D. Gestão ambiental na empresa. 2 ed. São Paulo. Ed. Atlas. 2011. 169p.

ELKINGTON, J. 1997. Cannibals with Forks: The triple bottom line of 21st century business. Capstone: Oxford.

HAWKEN, P.; LOVINS, A.; LOVINS, HUNTER. Capitalismo natural: criando a próxima revolução industrial. São Paulo: Cultrix-Amana-Key, 2000.

MACEDO, M. A. S., CASA NOVA, S. P.; ALMEIDA, K. (1999). Mapeamento e análise bibliométrica da utilização da análise envoltória de dados (DEA) em estudos das áreas de contabilidade e administração. In: ENANPAD, XXIII, Anais. Foz do Iguaçu: ANPAD.

MACPHERSON, I. (1996), Princípios cooperativos para o século XXI, Lisboa, INSCOOP.

MAPA - Ministério da Agricultura, Pecuária e Abastecimento. Disponível em: <http://www. agricultura.gov.br/cooperativismo-associativismo>. Acesso em 15 de Julho de 2014.

NAMORADO, R. (1993). Da cooperação ao direito cooperativo, Coimbra, Faculdade de Economia da Universidade de Coimbra.

OCB SESCOOP - Organização das Cooperativas Brasileiras. Disponível em: <http://www.ocb.org.br/ site/cooperativismo/index.asp $>$. Acesso em 15 jun. 2014.

OCB - Organização das Cooperativas Brasileiras. Orientação para constituição de cooperativas. 7 . ed., Brasília: OCB, 1998.

OLIVEIRA, D.P.R. Manual de gestão das cooperativas. 1. Ed. São Paulo: Editora Atlas, 2001.

PINHO, D. B.. A doutrina cooperativa nos regimes capitalista e socialista. São Paulo: Pioneira, 1966.

PINHO, D. B.. Que é cooperativismo. São Paulo. Editora S.A. São Paulo-SP, 1996.

ROSTAING, H. (1997). La bibliométrie et es techniques. Tolouse: Sciences de la Société; Marseille: Centre de Recherche Rétrospective de Marseille.

SACHS, I. NI: includente, sustentável, sustentado. Rio de Janeiro: Garamond, 2004. 
SEN, A. Desenvolvimento como liberdade. 5. ed. São Paulo: Companhia das letras, 2000.

SESCOOP - Panorama do Cooperativismo Brasileiro. Disponível em: <http://www.brasilcooperativo. coop.br/gerenciador/ba/arquivos/panorama_do_ cooperativismo_brasileiro__2011.pdf $>$. Acesso em 15 jun. 2014.

SILVA, M. R. (2004). Análise bibliométrica da produção científica docente do programa de pós-graduação em educação especial/UFSCar. Dissertação (Mestrado em Educação Especial) Universidade Federal de São Carlos, São Carlos, Brasil.

SINGER, Paul. Introdução à economia solidária. São Paulo: Fundação Perseu Abramo, 2002.

YOUNG, L. H. B.. Sociedades cooperativas: resumo prático. 8. ed. rev. e atual.Curitiba: Juruá, 2008.

WCED - Comissão Mundial sobre Meio Ambiente e Desenvolvimento: Nosso Futuro Comum, 1987. Disponível em: <http://www.un-documents.net/ wced-ocf.htm> Acesso em 15 de Julho 2014. 